\title{
O LETRAMENTO CRÍTICO E O LETRAMENTO DIGITAL: A WEB NO ESPAÇO ESCOLAR
}

\author{
Critical and Digital Literacies: The Web at School Environment
}

Edna Marta Oliveira da SILVA, UNINTER ${ }^{1}$

\begin{abstract}
RESUMO: As tecnologias digitais e a web têm sido temas amplamente debatidos na área da educação, uma vez que tais artefatos e o ciberespaço vêm possibilitando a democratização do conhecimento. Ainda hoje, no espaço escolar, há o encontro de diferentes gerações de professores e alunos que aprendem(ram) de modos distintos. São sujeitos que precisam negociar sentidos entre si, permeados por novos modos de se relacionar com o mundo e com o conhecimento. Além disso, ao mesmo tempo em que as tecnologias digitais favoreceram o acesso ao conhecimento, há uma expansão de ordem exponencial das informações que estão disponíveis em rede, o que exige dos sujeitos certas habilidades e estratégias para buscar as informações que sejam, de fato, as mais adequadas. Somado a esses fatores, para navegarmos em rede, o ciberespaço são necessários ainda outros procedimentos de escrita e leitura que estejam em consonância com o mundo digital. Sendo assim, com base nos estudos do letramento crítico e no letramento digital, este artigo apresenta algumas reflexões a respeito do ciberespaço, $a$ web e as novas relações que surgem dentro do espaço escolar.
\end{abstract}

PALAVRAS-CHAVE: TIC; We $b$; Letramento crítico; Letramento digital.

ABSTRACT: The digital technologies and the web are issues that have been widely debated in education, since they have allowed the democratization of knowledge. Even nowadays, different generations of teachers and students who learn/ have learned in different ways share in the school environment. They need to negotiate meanings with each other due to the new ways of relating with the world and with knowledge. Furthermore, while digital technologies have favored access to knowledge, there is a huge amount of information available on the web. Consequently, it is necessary certain skills and strategies to search the most appropriate information. In addition to these factors, the cyberspace also demands different kinds of writing and reading procedures that are in line with the digital world. Thus, based on critical and digital literacy studies, this article presents some reflections on the cyberspace, the web and the new relationships that arise within the school environment.

KEY WORDS: ICT; Web; Critical literacy; Digital literacy.

\section{INTRODUÇÃO}

A década de 1990 pode ser considerada como o marco da virada na história da humanidade em termos de comunicação e informação. Foi nessa época que a internet, criada inicialmente para servir a propósitos militares, tornou-se aberta ao público em geral. De forma tímida, a princípio, a rede mundial de computadores foi, em pouco tempo,

\footnotetext{
${ }^{1}$ Mestre em Letras. tecasilva@gmail.com
} 
ganhando espaço entre os mais variados tipos de usuários. Aproximou pessoas e povos dos mais diferentes lugares do mundo e desenhou uma nova trajetória das sociedades cujo carro-chefe é, sem dúvida, a comunicação mediada pelas tecnologias de informação e comunicação (as TIC). Indubitavelmente, somos seres comunicativos e a história da humanidade desenha-se em consonância com a forma como nos comunicamos uns com os outros. Refletir sobre como temos nos comunicado ao longo dos tempos é também um mergulho na própria história da humanidade. Dos gestos aos computadores e à internet, cada novo meio ampliou e modificou nossas possibilidades de comunicação.

Ao delinearmos tal panorama, é pertinente, então, pensarmos de que forma as TIC impactam espaços de instituições tradicionais aos quais são atribuídos papeis basilares na formação dos cidadãos, como é o caso da escola. É papel da escola contribuir para que os sujeitos possam - ao longo da educação formal institucionalizada no espaço escolar - dar conta de se expressar e se comunicar por meio dos mais diversos veículos de comunicação, especialmente aqueles que têm na escrita e na leitura o seu suporte de manifestação. Nesse sentido, questões relacionadas à alfabetização e ao letramento são componentes essenciais para que os sujeitos formados no âmbito escolar possam ser considerados, efetivamente, letrados. Se esse é o resultado que se espera de um sujeito ao passar pelo processo da educação formal, há de se pensar o que significa, então, ser um sujeito letrado.

Ser letrado é mais do que de estar apto a reconhecer letras e palavras. Significa não somente saber como usar um determinado código de escrita, mas também saber identificar as "práticas sociais manifestadas de formas diferentes em comunidades diferentes e em contextos diferentes" (SOUZA, 2011, p. 286) e usar a linguagem adequada em cada uma delas. A linguagem e o uso que dela fazemos é condicionada ao seu contexto de inserção e a escrita e o ato de ler um texto são atos intrínsecos da construção social de significados. Em outras palavras, aquilo que lemos/interpretamos de uma determinada forma é uma atribuição de sentidos que damos a um texto de acordo com a nossa visão de mundo.

Se a questão de letramento perpassa pelo contexto e pela prática social, estamos tratando de um mundo cujas leituras são de ordem rizomática como Alves (2011) aponta. Tais leituras são potencializadas pelo uso de tecnologias de informação e comunicação (TIC) que fazemos na atualidade, especialmente após o advento da web 2.0 que permitiu que nos tornássemos não são somente consumidores, mas também produtores e editores de conteúdo. A estrutura de rizoma, aos moldes do que Alves (2011) propõe, implica no cuidado em não cairmos na armadilha do "vale tudo" do consumo de informação e ideias, 
sem refletir sobre aquilo que nos é apresentado ao mesmo tempo em que há de se valorizar a pluralidade. Significa analisar criticamente e não aceitar "verdades absolutas" trazidas à baila em um texto.

Nesse sentido, a multiplicidade de leituras possíveis do mundo, sejam as minhas, as suas ou de comunidades diversas, dizem respeito a um mundo globalizado, complexo e conectado. É um mundo que tem uma diversidade mediada pelas TIC que aproximam pessoas de diferentes crenças e com as mais diversas visões de mundo. A tudo isso, somase a interatividade proporcionada pela $w e b$.

O próprio conhecimento foi democratizado e a sua relação com o espaço escolar mudou. Hoje, a escola não é mais a única a disseminar o conhecimento e, com isso, alteramse definitivamente as relações de poder entre os atores sociais presentes nesse espaço, pois o professor deixa de ser a única fonte de informação e de conhecimento para os aprendizes.

O desafio da educação neste século é, portanto, dar conta de tal panorama que agora se apresenta: um cenário permeado pelas TIC que tornou possível "montar e gerenciar grandes multidões globais com interesses comuns nas interações sociais" ${ }^{2 "}$ (AGHAEI; NEMATBAKHSH; FARSANI, 2012, p. 1), especialmente a partir da web 2.0. Apesar de já vivermos em tempos da web 4.0, o da "web simbiótica em que mente e máquinas humana pode interagir em simbiose " "AGHAEI; NEMATBAKHSH; FARSANI, 2012, p. 1), faço referência à web 2.0 por ter sido a partir de seu advento que houve a disseminação do uso das TIC nas interações sociais em maior escala e que demandaram novas formas de leitura e escrita. O que pretendo neste artigo é fazer uma reflexão a respeito de algumas questões referentes ao letramento digital necessário para que um usuário da web possa dar conta da comunicação no ciberespaço. Além disso, dada à quantidade de informações presentes na web, a busca pelo conhecimento exige do usuário a percepção do que pode ser ou não uma informação necessária. Assim, entende-se que estudos feitos sobre letramento crítico serão de valia para as discussões aqui apresentadas. Por fim, serão apresentadas algumas ideias sobre relações de poder que são (des)contruídas entre professores e alunos a partir do uso das ferramentas da web.

\footnotetext{
${ }^{2}$ No original: "[...] assembling and managing large global crowds with common interests in social interactions" (essa e as demais traduções ao longo do texto são de minha responsabilidade).

3 "[...] as symbiotic Web in which human mind and machines can interact in symbiosis".
} 


\title{
Sobre a web
}

Quando Pierre Lévy publicou seu livro “Cibercultura” na década de 1990, vivíamos ainda a expansão da internet e vislumbrávamos potencialidades que a web poderia nos proporcionar. Lévy (1999) foi um dos primeiros a perceber isso. Não que julgasse as redes sociais como a nossa tábua de salvação para os problemas do mundo; ao contrário, ele chama a atenção para o fato de que nem tudo o que está em rede é, necessariamente, bom. Lévy pede que sejamos abertos a ela e analisemos suas qualidades e seus problemas, levando-se em consideração as mudanças que dela se originam. Citando Albert Einstein, Lévy nos conta que o próprio Einstein, ainda na década de 1950, afirmava que o século XX testemunhou a eclosão de três grandes bombas: a demográfica, a atômica e a das telecomunicações. Lévy $(1999$, p, 13) corrobora as palavras de Einstein ao citar em seu livro, e de maneira muito apropriada, a ideia de um "segundo dilúvio" de informações proposta por Roy Ascott. Segundo Lévy (1999, p. 13),

\begin{abstract}
as telecomunicações geram esse novo dilúvio por conta da natureza exponencial, explosiva e caótica de seu crescimento. A quantidade bruta de dados disponíveis se multiplica e acelera. A densidade dos links entre as informações aumenta vertiginosamente nos bancos de dados, nos hipertextos e nas redes. Os contatos transversais entre os indivíduos proliferam de forma anárquica. É o transbordamento caótico das informações, a inundação de dados, as águas tumultuosas e os turbilhões da comunicação, a cacofonia e o psitacismo ensurdecedor das mídias, a guerra das imagens, as propagandas e as contrapropagandas, a confusão dos espíritos.
\end{abstract}

Podemos perceber que, ao longo dos anos, desde a publicação da obra de Lévy, suas percepções a respeito do tema puderam ser verificadas. Vale ressaltar que tais proposições foram sugeridas pelo autor em tempos de web 1.0, quando ainda era unidirecional e estática. Esse panorama é profundamente alterado quando surge a web 2.0. Vejamos do que se trata.

Cunhado no ano de 2004 por Dale Dougherty da O'Reilly Media, o termo web 2.0 relaciona-se à metáfora do dilúvio proposta por Ascott. É uma nova internet que surge, pois agrega recursos dos mais variados e que já existiam na rede. Tal foi o seu impacto nas sociedades que aspectos relacionados à privacidade, ética e segurança foram trazidas para dentro das relações sociais estabelecidas virtualmente, e passaram a ser tema de amplos debates, incluindo-se aí relações com o governo, educação, cidadania e comércio, para citar algumas (VALENTE; MATTAR, 2007). A criação das redes sociais na internet "talvez seja uma das maiores contribuições da web 2.0 no desenvolvimento humano" (VALENTE; MATTAR, 2007, p. 83), pois aproximou povos das mais diferentes origens que, 
provavelmente, jamais ser encontrariam se não fosse por meio das redes sociais on line. E isso é justamente o que difere a web 2.0 da web 1.0: as possibilidades de interação. Diz respeito aos recursos ali disponíveis e que nos permite transitar, ir e vir, selecionar, apagar, alterar informações disponíveis no ciberespaço. Não somos mais meros consumidores, mas também criadores de conteúdo (VASINDA; MCLEOD; MORRISON, 2007), pois não dependemos de conhecimentos específicos de linguagem de programação em HTML (Hypertext Markup Language), conhecimentos esses que diminuíam drasticamente o número de usuários habilitados para alterar conteúdos disponibilizados em rede. Todos os conteúdos da rede eram, na web 1.0, criados com base somente naquilo que as instituições queriam que seus usuários soubessem. Com a web 2.0, a relação entre usuários tornou-se dialógica, uma “[...] comunicação em duas vias [...] Ao usar blogs, wikis, podcasts e outras ferramentas da web 2.0, os indivíduos agora falam de igual para igual com empresas e organizações." (VASINDA; MCLEOD; MORRISON, 2007). Para Vasinda, McLeod e Morrison (2007), tal dialogicidade só não se realiza se não há vontade de produzir por parte do usuário. Se comparado aos tempos da web 1.0, "com todos os recursos da web 2.0, houve um avanço significativo em relação aos primórdios da internet, permitindo ao usuário melhor navegabilidade, maior interatividade, e a funcionalidade equivalente ao desktop" (VALENTE; MATTAR, 2007, p. 84). Democratizou-se, dessa forma, não somente a produção de conteúdo, mas também de significados e, com isso, novas regras de comunicação são igualmente estabelecidas (VASINDA; MCLEOD; MORRISON, 2007).

Em se tratando da produção de conteúdos, cabe ressaltar que a web 2.0 permitiu-nos manipular os já existentes - e aqui cabe enfatizar, não somente no sentido negativo implícito no termo - tornando possível a remixagem de toda e qualquer matéria-prima disponível na rede (VALENTE; MATTAR, 2007). De acordo com Lankshear e Knobel(2011), a ideia de remixagem está associada à combinação e manipulação de artefatos culturais pré-existentes, de modo a criar novos produtos. Para os autores, essa é uma condição essencial das culturas e afirmam que se não há remixagem, não há cultura, pois "remixamos significados toda vez que pegamos uma ideia ou um artefato ou uma palavra e a integramos em algo que estamos dizendo ou fazendo ou sendo no momento"5 (LANKSHEAR; KNOBEL, 2011, p. 97). Um exemplo desse processo é o que acontece

\footnotetext{
4 “[...] two-way communication[...]By using blogs, wikis, podcasts, and other Web 2.0 tools, individuals now have an equal voice with business and organizations".

5 "we remix meanings every time we take an idea or an artifact or a word and integrate it into what we are saying or doing or being at the time".
} 
no espaço acadêmico, quando produzimos textos escritos a partir da ideia de outros autores e, dessa forma, aprendemos a escrever. A partir da web 2.0, a remixagem passa a ter a característica digital e incluímos incluir sons e imagens, sejam elas estáticas ou em movimento. O conceito de produção escrita, portanto, assume outra característica, conforme aponta Koman (2005 apud LANKSHEAR; KNOBEL, 2011, p. 100):

Quando você diz a palavra 'escrita' para aqueles acima dos 15 anos de idade, nosso conceito de escrever é escrever com texto...Mas se você pensar nas maneiras que os garotos abaixo dos 15 - que usam a tecnologia digital - pensam sobre escrita, você sabe, escrever um texto é somente uma forma de escrever e nem sempre é a maneira mais interessante. As formas mais interessantes estão usando cada vez mais as imagens, som e vídeo para expressar ideias. ${ }^{6}$

Há, com isso, uma expansão do conceito de escrita, pois estão envolvidas práticas de produção, troca e negociação de sentidos em textos remixados digitalmente (LANKSHEAR; KNOBEL, 2011) e que podem empregar somente uma ou várias mídias. E todas são publicáveis e acessíveis aos usuários da web. O papel de produtor de conteúdo confunde-se com o de leitor, de editor e colaborador. Se aplicarmos tais conceitos à área da educação, percebe-se que "a habilidade para acessar e publicar conteúdo com facilidade nos força a repensar o que esperamos de nossos alunos, e inclusive o que significa ensinar a aprender", pois ocorre "não apenas a separação entre usuário e autor, mas também a separação entre aluno e autor. (VALENTE; MATTAR, 2007, p. 85).

Se houve esse deslocamento do papel que o aluno desempenha num cenário como esse, devemos considerar - e até mesmo questionar - qual seria o papel que se pode esperar do professor. O fato é que o acesso e a publicação de conteúdos por qualquer pessoa que saiba usar as ferramentas disponíveis na web implica, em termos educacionais, revermos o que significa, no século XXI, ensinar e aprender. Deixamos de ser leitores passivos de conteúdos alheios; queremos, agora, também participar e compartilhar informações e conhecimento. Na opinião de Mcleod e Vasinda (2008) isso empodera uma comunidade, pois o uso das ferramentas da web expande as práticas sociais e oferece oportunidades de se criar coletivamente significados e valores sob uma ótica construtivista.

A interatividade que surgiu com a web 2.0 fez surgir novas formas de escrita usando a tela do computador. A escola não pode "dar as costas" a esses novos gêneros textuais

\footnotetext{
6 "When you say the word writing, for those of us over the age of 15, our conception of writing is writing with text...But if you think about the ways kids under 15 using digital technology think about writing - you, know, writing with text is just one way to write, and not even the most interesting way to write. The most interesting ways are increasingly to use images and sound and video to express ideas".
} 
mediados pelas TIC, tais como blogs, fanfics, mashups e remixes, que fazem uso de recursos visuais e sonoros, associados ao uso da escrita. Sousa (2007) cita Marcuschi $(2004)^{7}$ como um dos pesquisadores sobre questões relativas à escrita e à oralidade e que observa o hibridismo característico da escrita em suporte digital, aproximando-a da fala. Essa aproximação tem sido um tema amplamente debatida, pois há um certo temor de que a escrita mediada pelas TIC - dada as suas especificidades - acabe por interferir negativamente na escrita em termos fonológicos, morfológicos e sintáticos (Sousa, 2007). Entretanto, Marcuschi (2007 apud Sousa, 2007) aponta para a realidade que envolve a escrita digital, que vai além de questões internas à língua, em termos de estrutura ou forma. Para o autor, em se tratando da escrita digital, o foco deve ser sobre os fatores externos à escrita e que envolvem aspectos sociais, culturais, históricos e tecnológicos. Ou seja, "as formas de textualização que aparecem na internet devem ser analisadas com vistas aos processos de produção de sentido e de relações interpessoais” (SOUSA, 2007, p. 201).

A questão que surge, então, é de que forma um indivíduo poderá ser considerado "letrado" levando-se em consideração o fato de vivermos, atualmente, em um contexto no qual as TIC surgem como uma forma de expressão diferenciada daquela que usa o suporte impresso. É um novo tipo de letramento que inspira um olhar mais cuidadoso por parte da escola. Para Pereira (2005, p. 17), "precisamos dominar a tecnologia para que, além de buscarmos a informação, sejamos capazes de extrair conhecimento" e lidar com o instrumental que a web exige conhecimentos que vão além do domínio da língua enquanto código. Precisamos não somente "digitar" textos, mas também saber "navegar" na rede. A metáfora do "navegar" é muito pertinente, pois tal como no mar real, não basta termos os artefatos adequados para não ficarmos à deriva; devemos, antes de tudo, saber quando e como utilizá-los. Se quisermos buscar e construir o conhecimento na rede, devemos, obrigatoriamente, saber como e onde encontrar as informações das quais necessitamos. É nesse contexto que as questões de letramento, antes pertinentes à oralidade e à escrita, ampliam-se no contexto digital e serão tratadas a seguir.

\section{O letramento digital}

Ser letrado digitalmente, em um sentido mais abrangente, significa estar apto a desempenhar funções e executar ações que envolvam artefatos eletrônicos e digitais.

\footnotetext{
${ }^{7}$ MARCUSCHI, L.A. Gêneros textuais emergentes no contexto da tecnologia digital. In: MARCUSCHI, L. A. e XAVIER, A.C. (orgs.) Hipertexto e gêneros textuais. Rio de Janeiro: Lucerna, 2004, pp. 13-67.
} 
Incluem-se aí não somente computadores, mas também telefones celulares, $C D$ players, filmadoras e quaisquer outros equipamentos que envolvam o mesmo tipo de tecnologia. Além disso, um indivíduo digitalmente letrado deve dar conta da escrita e leitura de códigos, sejam eles verbais ou não, presentes no mundo virtual (XAVIER, 2011). O conceito de leitura, portanto, em se tratando de letramento digital, expande-se, pois imagens e sons são acrescidos ao texto escrito na interação com o outro, para dar significados ao mundo. De acordo com Xavier (2011, p. 6), "o grau de letramento digital do sujeito cresce à medida que aumenta o domínio dos dispositivos tecnológicos que ele emprega em suas ações cotidianas". Em outras palavras, ser letrado digitalmente não está relacionado ao fato de sabermos utilizar a tecnologia em si apenas, mas de utilizá-las nas diferentes práticas sociais por ela mediadas e circulantes no meio digital ${ }^{8}$.

Nesse sentido, não se pode negar que a produção escrita e a leitura no ciberespaço tomaram proporções incomensuráveis, dada a facilidade de acesso a esse novo mundo com o simples uso de um gadget $^{9}$ conectado à internet. Nunca se leu ou se escreveu tanto com o uso das tecnologias digitais, seja por meio de mensagens de textos, blogs, sites de notícias, fóruns de discussões, chat rooms ou em redes sociais, tais como Facebook, Twitter ou Whatsapp. Foi com o surgimento das TIC que as questões a respeito de quem é esse leitor/produtor de conteúdos passaram a ter relevância no rol das discussões acadêmicas, uma vez que ainda não há um consenso sobre essa nova forma de letramento e, muito menos, sobre os "aspectos instrucionais envolvidos em seu ensino" (VIEIRA, 2007, p. 244).

Inúmeras pesquisas têm sido realizadas e que envolvem os processos de leitura e escrita, pois entende-se que são habilidades necessárias para que ocorra o ensino e a aprendizagem em todas as áreas do conhecimento. Obviamente, no sentido restrito de letramento, apontado por Corrêa (2001), não podemos desconsiderar a questão do código escrito em si nas fases iniciais da alfabetização; é necessário (re)conhecermos o código, seus sons, suas letras e palavras - e as relações entre elas - antes de serem exigidas outras habilidades comunicativas. Esse é o sentido sobre o qual estudos na área de letramento têm

\footnotetext{
${ }^{8}$ Para mais detalhes sobre letramento digital e práticas sociais, ver trabalho de SILVA (2014): Por uma gramática do audiovisual: como videogames podem ajudar? . Disponível em: http://www.comunidadesvirtuais.pro.br/seminariojogos/files/GAMES_GRAM\%C3\%81TICA\%20DO\%20AUDIOVISUAL_CORRE\%C3\%87\%C3\%83O_FI M.pdf >. Acesso em 04 jul. 2014.

${ }^{9}$ Gadget, segundo o dicionário Aulete, é um "dispositivo mais engenhoso do que útil ger. eletrônico ou de pilha”. Disponível em: < http://aulete.uol.com.br/gadget> Acesso em 04 jul. 2014.
} 
colocado seu foco de pesquisa na escrita e na leitura, e que diferenciam um sujeito letrado de um não letrado. Para Signorini (2011, p. 124), “estamos compreendendo as práticas de letramento como o conjunto de ações e, que envolvem o uso da leitura e da escrita e que integram a dinâmica da vida cotidiana dos indivíduos e dos grupos de uma dada comunidade, ou de diferentes comunidades".

Aqui temos também a importância dada por Signorini (2011) à prática social como algo intrinsicamente relacionada à noção de letramento, em consonância com as discussões de Souza (2011), citadas anteriormente. Signorini (2011, p. 124-125) ainda destaca duas convicções básicas em relação ao tema, apontadas por diferentes pesquisadores. A primeira, diz respeito

ao "caráter sócio histórico de toda atividade de uso da escrita, bem como saberes, valores e das instituições que a sustentam. A segunda convicção é a da dimensão processual de toda escrita quando apreendida no contexto múltiplo e variado das práticas de comunicação social em sentido amplo.

O caráter sócio histórico da atividade escrita mencionado por Signorini (2011, p. 125) equivale a dizer que as práticas que fazem uso da escrita mudam ao longo do tempo e do espaço,

pois estão sempre atreladas à história individual do escrevente/leitor (papéis assumidos, posição social, objetivos, etc) e da(s) comunidades de que participa (estruturas de ordem social e política, divisão de trabalho, tradições culturais, etc), bem como aos diferentes campos de atividades do cotidiano e suas respectivas instituições de referência.

Em outras palavras, temos que compreender que, para cada espaço, há uma forma de ler/escrever e produzir sentidos e significados que fazem parte de um determinado contexto, tanto social quanto historicamente situado. A produção de escrita e da leitura mediada pelas TIC podem também ser percebidas sob essa mesma ótica. Palavras tais como chats, e-mails, blogs, fotologs, wikis, podcats, homepages, não existiam há alguns anos, pois não havia as formas de socialização que temos hoje no ciberespaço e que "provocam alguma 'perturbação' na ordem escolar.” (ARAÚJO, 2007, p. 16). A cada novo gênero textual no espaço virtual da $w e b$, surge "um hibridismo não previsto pelos padrões de teorização e avaliação da escrita prestigiados nas instituições escolares e acadêmicas" (SIGNORINI, 2011, p. 98). Tal hibridismo é evidente quando observamos a aproximação da fala com a escrita no ciberespaço, espaço esse no qual as "mensagens via internet [...] são percebidas como objetos mistos, no sentido de híbridos ou heterogeneamente 
constituídos, como costumam ser percebidas as mensagens dos internautas" (SIGNORINI, 2011, p. 99).

Os impactos dessa nova forma de letramento no ciberespaço não podem, portanto, passar incólumes. São desafios a serem enfrentados por aqueles que trabalham com línguas, seja materna ou estrangeira. $\mathrm{O}$ sentimento de insegurança dos professores em relação ao uso da TIC em suas práticas pedagógicas foi observado por Araújo (2007), a partir da fala de seus ex-alunos do curso de Letras, que usavam a expressão tsunami digital para se referir à inserção dos artefatos digitais e da web na esfera educacional. Para o autor, "comparar as práticas discursivas em ambiente digital a uma catástrofe [...] é, no mínimo, um grito de socorro [...] que ainda desconhece o potencial pedagógico do computador conectado à internet" (ARAÚJO, 2007, p. 16). Cada nova tecnologia que surge é um reflexo de seu tempo e, ainda que gere desconfiança, causa impacto e exige mudança de hábitos dos indivíduos.

O fato é que escrever/ler é tão necessário no ciberespaço quanto no suporte de papel e disso não se pode escapar. Com as transformações promovidas pelas TIC, vieram também as transformações e novas formas de letramento. Para Vieira (2007), a escola não pode eximir-se da sua responsabilidade em fornecer condições aos educandos na promoção do letramento digital. Entretanto, a autora parte do pressuposto que a formação docente adequada é um fator essencial e necessário para que isso ocorra, efetivamente, no espaço escolar, sem deixar à parte, é evidente, as questões linguísticas que envolvem a leitura e a escrita. A autora equipara o investimento na formação docente a um mesmo nível de importância ao dos investimentos referentes à inclusão digital. Mesmo tendo a internet proporcionado maior liberdade ao leitor/redator, o docente "ainda é a referência mais importante do leitor em formação" (VIEIRA, 2007, p. 265).

A comunicação eletrônica, aliada à visual, criaram novas necessidades utilitárias essa é uma característica da era pós-tipográfica, segundo Semali (2003 apud VIEIRA, 2007, p. 264). Com a web, temos ao nosso dispor uma infinidade de informações possíveis de serem acessadas a qualquer momento. Por outro lado, ao mesmo tempo em que o acesso ao conhecimento e às informações por meio de um gadget conectado à internet seja mais fácil, o número exponencial de sites disponíveis para consulta pode mais confundir do que ajudar. O usuário da rede corre o risco de ficar "à deriva" durante sua "navegação". Portanto, a habilidade de escolher ou encontrar aquilo que é realmente necessário é parte do que significa ser letrado digitalmente e isso exige do leitor/redator ativo no mundo 
virtual um olhar mais crítico sobre o processo de seleção de conteúdos. Esse é também o pensamento de Mcleod e Vasinda (2008, p. 5). Para as autoras,

\begin{abstract}
quando o volume de informações disponíveis ao simples clique de uma tecla, aprendizes precisam desenvolver habilidades e estratégias para determinar a qualidade, credibilidade, validade, propósito e a intenção da informação que pode ser acessada facilmente. O letramento crítico é uma maneira de avaliação textual para determinar o ponto de vista ou intenção do autor, as razões pelas quais o texto foi escrito a partir de um ponto de vista em particular, e os motivos pelos quais certos elementos relacionados ao texto foram incluídos e/ou excluídos ${ }^{10}$.
\end{abstract}

Portanto, o letramento crítico é outro ponto a ser levado em conta quando nos propomos a discutir o letramento digital. Ao agregar os estudos relativos a essas duas áreas, talvez seja possível fornecer subsídios necessários para que um sujeito possa se tornar realmente ativo na web.

\title{
O letramento crítico
}

Os significados daquilo que lemos são atribuídos de acordo com a visão de mundo de um determinado grupo social e isso implica em formas de ler e escrever diferenciadas, em consonância com o espaço e o tempo em que ocorrem. Por outro lado, o fato de contextualizarmos um texto nos âmbitos social e cultural, não significa que devemos desvelar a intenção do autor contida em um texto, pois não há um único modo de leitura e, muito menos, um modo certo ou errado. Souza (2011, p. 291-292) aponta para o fato que esse foi o procedimento utilizado, ao longo de vários anos, e cita as consequências de tal atitude:

\begin{abstract}
Não assumíamos a responsabilidade pela nossa interpretação, não víamos que nós, enquanto leitores, ao identificarmos o significado de determinado texto, nós estamos contribuindo e assumindo a responsabilidade pela nossa interpretação [...] Você tem que assumir a responsabilidade pela sua leitura, porque a sua leitura vai ter consequências sociais.
\end{abstract}

Relacionando as palavras deste autor às práticas docentes, devemos assumir a responsabilidade, enquanto professores, de chamar a atenção dos aprendizes com relação aos caminhos possíveis para sair do senso comum, por meio da reflexão a respeito de suas

\footnotetext{
10 "With the barrage of information available at the stroke of a single key, learners need to develop skills and strategies to determine the quality, reliability, validity, purpose, and intent of the information that they can easily access. Critical literacy is a way of evaluating text in terms of determining the author's perspective or intent, the reasons the text was written from a particular perspective, and the reasons certain elements related to the text were included and/or excluded".
} 
próprias ideias, pois não há uma única verdade. Nesse sentido, concordo com Jordão (2013, p. 82-83) em relação ao letramento crítico, quando essa autora afirma que

no letramento crítico, para sermos críticos e desenvolvermos criticidade precisamos perceber que nossas próprias crenças e valores também são sócio historicamente construídos, que nossos próprios textos estão ancorados nos contextos discursivos que são produzidos.

Podemos dizer, portanto, que tanto Souza (2011) quanto Jordão (2013) desempoderam o autor de um determinado texto, uma vez que esse mesmo texto pode ter uma multiplicidade de sentidos, "muitas verdades construídas ideologicamente e partilhadas socialmente" (JORDÃO, 2013, p. 76). O leitor, em contrapartida, assume um “papel mais poderoso" (MCLEOD; VASINDA, 2008, p. 5) se comparado a uma visão mais tradicional de leitura, que prevê somente a decifração de signos linguísticos. Para as autoras,

quando os leitores consideram assuntos além do texto, questionam a perspectiva e a intenção do autor e refletem sobre como eles mudaram por causa do encontro com o texto, eles estão abordando a leitura a partir de uma perspectiva ou postura crítica $^{11}$ (MCLEOD; VASINDA, 2008, p. 5).

Para entendermos o letramento crítico em uma era de multiplicidades, complexidades e incertezas identitárias, precisamos considerar o fato de que as TIC foram, em parte, as responsáveis pelos impactos em vários setores da sociedade. A forma como nos comunicamos uns com os outros, no século XXI, colocou em contato grupos dos mais diversos, gerando uma das grandes ondas "tsinumânicas" - para usar o termo cunhado pelos ex-alunos do prof. Araújo (2007) - dada a velocidade com que trocas de informações e conhecimento ocorrem na atualidade.

Ao navegarmos pela rede, tornamo-nos parte integrante dos mais diversos tipos de comunidades on line, grupos esses que se identificam entre si por meio de identidades compartilhadas entre seus membros. Pensando em termos de web e na complexidade da comunicação que ocorre nesse espaço, faz-se também necessário levarmos em consideração dois aspectos fundamentais: o suporte utilizado para que a comunicação entre os membros de um grupo no ciberespaço se realize e o tipo de habilidade necessária para o uso das TIC envolvidas num evento comunicativo. Comunicar é, portanto, um ato muito mais complexo no século atual. Para Souza (2011), a complexidade do mundo reflete-se

\footnotetext{
11 "When readers consider issues beyond the text, question the author's perspective and intent, and reflect upon how they are changed because of the encounter with the text, they are approaching reading from a critical perspective or stance".
} 
na complexidade dentro de cada indivíduo. "Essa é a complexidade que o mundo rizomático de interconectividade nos traz" (SOUZA, 2011, p. 285). E por ter a comunicação no ciberespaço tal característica rizomática, significados não são somente construídos social e culturalmente, mas também distribuídos em rede. A complexidade é uma característica essencial do mundo virtual, mundo esse onde "o que se enfatiza aqui é a produção e a busca de conhecimento. Não é mais o consumo de conhecimento preestabelecido; o que se valoriza mais é a capacidade de buscar conhecimento" (SOUZA, 2011, p. 289).

A web é o espaço no qual a questão da autoria passa a ser questionada, uma vez que a interatividade oriunda de tal espaço permite a adição, edição ou retirada de conteúdos de forma individual e, ao mesmo tempo, colaborativamente. Os resultados são, portanto, compartilhados por todos aqueles que usem de sua agência, enquanto usuários da rede, para fazer toda e qualquer alteração que julgarem necessárias. Nesse sentido, a web "tem a vantagem adicional que seus usuários podem unir-se ao diálogo a qualquer momento e/ou adicionar uma perspectiva singular ao tópico"12 (MCLEOD; VASINDA, 2008, p. 6). Sobre o mesmo tema, McLaughlin e DeVoogd ${ }^{13}$ (2004 apud MCLEOD; VASINDA, 2008) mencionam o fato de as ferramentas que foram disponibilizadas com a web 2.0 terem transformado o usuário em "prosumidor ${ }^{14}$ ", deixando para trás o seu papel de mero consumidor de conteúdos para tornar-se também produtor de conteúdos, se assim o desejar.

Além disso, a dinâmica da $w e b$, com a sua multiplicidade de pontos de vista, permite aos usuários não somente avaliar a perspectiva de um autor, mas também comparar com seus próprios pontos de vista. Há um apagamento da figura do especialista, pois a sua visão de mundo pode ser comparada - e até mesmo contestada - por aqueles que navegam na rede. Há, nesse sentido, uma alteração nas relações de poder: o controle sai da mão de um único especialista ou autor e passa a ser distribuído por entre "prosumidores”. Isso também irá se refletir no âmbito educacional, uma vez que o conhecimento, democratizado e ao alcance de qualquer sujeito que tenha acesso à web e suas ferramentas, escapa ao controle daquele ator social cuja função é ensinar: o professor. Agora, aquele que aprende - o aluno

\footnotetext{
12 " [...] has the additional advantage that users may join the dialogue at any point and/or add a unique perspective to the topic".

${ }^{13}$ McLaughlin, M; De Voogd, G. Critical literacy: enhancing students' comprehension of text. New York, NY: Scholastic, 2004.

14 "Prosumer". Neologismo sobre o fato de o usuário da web ser, ao mesmo tempo, produtor e consumidor de conteúdos.
} 
- pode também buscar pelo conhecimento quando navega pela internet. A figura do professor, antes a única fonte de conhecimento para o aluno, perde seu lugar no contexto do mundo digital. Num campo tão volátil quanto é o da web, as relações de poder são, dessa maneira, reconfiguradas e merecem um olhar mais cuidadoso sobre elas.

\section{As relações entre alunos e professores na $w e b$}

É indiscutível a liberdade de expressão e as possibilidades de comunicação que as TIC e a web proporcionam aos seus usuários. As mudanças promovidas por essas ferramentas transformaram a relação com o conhecimento; surgem novas formas de aprender em rede e, com isso, a escola - enquanto instituição da promoção do conhecimento - teve sua função social modificada pelas novas relações que surgem. Lévy (1999, p. 160-161) discute as mudanças a partir da sua percepção em relação ao ciberespaço. Diz o autor que

na Web, tudo se encontra no mesmo plano. E, no entanto, tudo é diferenciado [...] As metáforas centrais da relação com o saber são, hoje, [...] a navegação e o surfe, que implicam uma capacidade de enfrentar as ondas, redemoinhos, as correntes e os ventos contrários em uma extensão plana, sem fronteiras e em constante mudança. Em contrapartida, as velhas metáforas da pirâmide (escalar a pirâmide do saber) da escala ou do cursus (já totalmente traçado) trazem o cheiro das hierarquias imóveis de antigamente.

Se papeis foram alterados e o conhecimento (assim como a sua produção) democratizou-se de uma forma nunca antes vivenciada cabe, então, questionarmos até que ponto as atuais políticas de educação podem dar conta dessa nova relação com o saber que surge. Conforme aponta Lévy (1999, p. 167), “com esse novo suporte de informação e comunicação emergem gêneros de conhecimento inusitados, critérios de avaliação inéditos para orientar o saber, novos atores na produção e tratamento dos conhecimentos”.

A escola tem sido reconhecida há muito como o espaço tradicional da difusão do conhecimento, cuja função social é o da transmissão da cultura reconhecida como válida por um determinado grupo social. A relação entre a escola e as tecnologias não é algo novo ou recente, pois "os vínculos entre conhecimento, poder e tecnologias estão presentes em todas as épocas e em todos os tipos de relações sociais" (KENSKI, 2007, p. 17). A articulação entre tais elementos - conhecimento, poder e tecnologia - é propiciada pela educação, representada pelo espaço escolar. É também esse espaço que favorece o acesso ao mundo do trabalho e à formação cidadã, de modo a garantir aos sujeitos certa qualidade 
de vida. Nesse sentido, em um mundo globalizado cujo acesso é facilitado pelo uso que se faz das TIC, a escola deve assumir o seu papel como socializadora das inovações digitais. Mas alguns pontos devem ser levados em consideração.

O primeiro deles é que a mera divulgação de uma inovação pela mídia não garante que os sujeitos - professores e alunos - farão pleno uso de tais recursos, nem tampouco que irão ter acesso a elas. Para que a escola possa cumprir seu papel, faz-se necessário que as TIC sejam incorporadas eficazmente às práticas pedagógicas. E, nesse sentido, podemos esbarrar na falta de infraestrutura do espaço escolar com relação a laboratórios de informática ou na falta de formação docente adequada para o uso das TIC.

O segundo ponto diz respeito a uma parcela dos alunos que já faz uso das TIC em contextos extraclasse. E, nesse caso, pode haver um distanciamento entre alunos e professores, caso estes últimos não estejam familiarizados com uso desses artefatos digitais. Os alunos "nativos digitais", para usar a expressão de Prenski (2001) ao se referir aos sujeitos nascidos após a década de 1980 e que cresceram num contexto digital - trazem para dentro do espaço escolar suas experiências com as tecnologias digitais e, às vezes, podem demonstrar maior receptividade em relação aos mais diversos artefatos eletrônicos do que os próprios docentes. Não se pode ignorar o fato que ainda existe uma geração de professores que pensam de forma "analógica" se comparados ao novo perfil dos alunos. Conforme aponta Mattar (2012, p. 10), “nossos alunos [...] são hoje falantes nativos da linguagem digital dos computadores, videogames e Internet”. Mesmo considerando a possibilidade de um professor ser um "imigrante digital" - indivíduo oriundo da era prédigital e que se adaptou ao contexto da era digital - Mattar (2012) questiona se ele é capaz de cumprir sua função enquanto educador de uma geração que aprende de forma diferente. É necessário dar conta de uma geração de alunos que "sabem que, no momento em que quiserem aprender, existem ferramentas disponíveis para ajudá-los” (MATTAR, 2012, p. 11). Abre-se uma lacuna entre gerações e, ao mesmo tempo, ocorre um forte deslocamento do papel docente no contexto digital: por uma lado, aulas expositivas, tradicionais e, por outro, a possibilidade de os professores perderem seu lugar de destaque para o conhecimento disseminado pela web. Tapscot (1998, p. 304 apud KENSKI, 2007, p.49) observa que "pela primeira vez num dado domínio, os estudantes viram professores e os 
professores, alunos. A dinâmica do poder alterou-se para sempre" ${ }^{\text {"15 }}$ Em outras palavras, isso agora é um caminho sem volta.

Ficamos com a impressão que a figura do docente caiu no ostracismo, graças às tecnologias digitais. No entanto, o contexto atual demanda uma revisão - e por que não dizer, reinvenção - das práticas pedagógicas a fim de darmos conta da nova geração de alunos que surge. Lévy (1999, p. 171), já antecedendo as novas relações de poder que oriundas da cibercultura, afirma que o papel do professor será o de um "animador da inteligência coletiva". Para o autor:

\begin{abstract}
a principal função do professor não pode mais ser uma difusão dos conhecimentos, que agora é feita de forma mais eficaz por outros meios. Sua competência deve deslocar-se no sentido de incentivar a aprendizagem e o pensamento. O professor torna-se um animador da inteligência coletiva dos grupos que estão a seu encargo. Sua atividade será centrada no acompanhamento e na gestão de aprendizagens: o incitamento à troca dos saberes, a mediação relacional e simbólica, a pilotagem personalizada dos percursos de aprendizagem etc.
\end{abstract}

Sendo assim, concordo com Staa (2011) a respeito dos novos papeis que são redesenhados a partir desse novo contexto digital que se insere no espaço escolar. Não importa quais mudanças ocorram, mas o papel do professor sempre será o de auxiliar seus alunos na senda do aprendizado, mediado ou não pelas TIC. Com a inserção das TIC, o volume de conteúdos e informações que caberiam ao professor administrar passa a ser distribuído em rede e o professor desincumbe-se da obrigação de dar conta de tal árdua tarefa. Seu tempo, agora, pode ter como foco a observação e a orientação mais acurada de seus alunos, pois "tirando do professor a obrigação de transmitir conteúdos [...] a cibercultura pode ajudar todos a aprender mais e a se conhecer mais" (STAA, 2011, p. 38).

\title{
Considerações finais
}

O mundo globalizado do qual somos parte optou por um caminho rumo à inserção das TIC de tal maneira que, nos dias de hoje, torna-se impraticável imaginar uma sociedade sem elas, aos moldes de como era há somente algumas décadas. Nossas formas de comunicar e de nos relacionarmos uns com os outros mudaram definitivamente, graças aos avanços no campo da interação e interatividade originados da cibercultura, representada pela web.

\footnotetext{
15 TAPSCOTT, D. Growing up digital: the rise of the new generation. Nova York: McGraw Hill, 1998. Tradução feita por Kenski (2007).
} 
A escola, por ser o local cuja função é o de formar cidadãos plenos para atuarem no mundo, precisa readequar a sua posição de centro disseminador do conhecimento, uma vez que o conhecimento, agora, está distribuído em rede e alcance ao de qualquer sujeito com acesso à web. Nesse sentido, cabe ao professor fazer a sua parte e tentar entender a nova geração de nativos digitais que surge e que traz, para dentro do espaço escolar, sua experiência altamente produtiva com as TIC em seu dia a dia. Tal como dito por Freire (1987), o professor não pode mais se isolar na sua "torre de marfim" e ignorar o conhecimento do mundo digital de nossos alunos. Sejamos, efetivamente, seres da práxis, do querer-fazer.

Nesse sentido, e para ajudar-nos nesse caminhar pela cibercultura, questões a respeito de letramento digital e letramento crítico podem oferecer algum suporte para compreendermos as possibilidades oriundas do mundo digital.

\section{Referências Bibliográficas}

AGHAE, S.; NEMATBAKHSH, M.A.; FARSANI, H. K. Evolution of the World Wide Web: from Web 1.0 to web 4.0. International Journal of Web \& Semantic Technology (IJWesT), v.3, nº.1, jan. 2012. Disponível em: 〈http://airccse.org/journal/ijwest/papers/3112ijwest01.pdf > Acesso em 12 jun. 2016.

AULETE DIGITAL. Gadget. Disponível em: <http://www.aulete.com.br/gadget > Acesso em 13 jun. 2016.

ARAÚJO, J.C. Internet \& Ensino: novos gêneros, outros desafios - Introdução. In: ARAÚJO, J.C. (org). Internet e Ensino: novos gêneros, outros desafios. Rio de Janeiro: Lucerna, 2007. p. 15-17.

CÔRREA, M.L.G. Letramento e heterogeneidade da escrita no ensino de português. In: SIGNORINI, I. (org). Investigando a relação ora/escrito e as teorias do letramento. Campinas, SP: Mercado das Letras, 2001, pp. 135-166 (Coleção Ideias sobre a Linguagem).

FREIRE, P. Pedagogia do Oprimido. $17^{\mathrm{a}}$ ed. Rio de Janeiro: Paz e Terra.

JORDÃO, C.M. Abordagem comunicativa, pedagogia crítica e letramento crítico farinhas do mesmo saco? In: ROCHA, C.H.; MACIEL, R. F. (orgs). Língua Estrangeira e Formação Cidadã: por entre discursos e práticas. Campinas, SP: Pontes Editores, 2013. pp. 69-90 (Coleção Novas Perspectivas em Linguística Aplicada Vol. 33).

KENSKI, V.M. Educação e Tecnologias: o novo ritmo da informação. Campinas,SP: Papirus, 2007. (Coleção Papirus Educação).

LANKSHEAR, C.; KNOBEL, M. New Literacies: everyday practices and social learning. Bershire, England: OUP; Mc Graw Hill, 2011. 
LÉVY, P. Cibercultura. Trad. de Carlos Irineu Costa. São Paulo: Ed. 34, 1999.

O que é o virtual?. $6^{\text {a }}$ ed. Trad. de Paulo Neves. São Paulo: Ed. 34, 2003.

MATTAR, J. Games em educação: como os nativos digitais aprendem. São Paulo: Cengage Learning, 2012 (Série Educação e Tecnologia).

MARCUSCHI, L.A. Gêneros textuais emergentes no contexto da tecnologia digital. In: MARCUSCHI, L. A. e XAVIER, A.C. (orgs.) Hipertexto e gêneros textuais. Rio de Janeiro: Lucerna, 2004, pp. 13-67.

MCLAUGHLIN, M; DE VOOGD, G. Critical literacy: enhancing students' comprehension of text. New York, NY: Scholastic, 2004.

PEREIRA, J. T. Educação e Sociedade da Informação. In: COSCARELLI, C. V.; RIBEIRO, A.E. (orgs.). Letramento digital: aspectos sociais e possibilidades pedagógicas. Belo Horizonte: Ceale; Autêntica, 2005. pp.13-24.

PRENSKY, M. Digital Natives, Digital Immigrants. Bradford: MCB University Press, v. $9, \quad \mathrm{n}^{\circ} \quad 5, \quad$ out. 2001. Disponível em: < http://www.marcprensky.com/writing/Prensky\%20\%20Digital\%20Natives,\%20Digital\% 20Immigrants\%20-\%20Part1.pdf> Acesso em 16 dez. 2013.

SIGNORINI, I. Construindo com a escrita "outras cenas de fala". In: SIGNORINI, I. (org). Investigando a relação ora/escrito e as teorias do letramento. Campinas, SP: Mercado das Letras, 2001. pp. 97-134 (Coleção Ideias sobre a Linguagem).

SILVA, E. M. O. Por uma gramática do audiovisual: como vídeo games podem ajudar? 2014. Disponível em: < http://www.comunidadesvirtuais.pro.br/seminariojogos/files/GAMES_GRAM\%C3\%81T ICA\%20DO\%20AUDIOVISUAL_CORRE\%C3\%87\%C3\%830_FIM.pdf> Acesso em 04 jul. 2014.

SOUSA, S.C.T. As formas de interação na internet e suas implicações para o ensino de língua materna. In: ARAÚJO, J.C. (org). Internet e Ensino: novos gêneros, outros desafios. Rio de Janeiro: Lucerna, 2007. pp. 196-204.

SOUZA, L. M. T.M. O professor de inglês e os letramentos no século XXI: métodos ou ética? In: JORDÃO, C. M.; MARTINEZ, J. Z.; HALU, R.C. (org.) Formação desformatada - práticas com professores de língua inglesa. Campinas, SP: Pontes Editores, 2011. pp. 279-303.

STAA, B.V. Tecnologia na educação: reflexões sobre docência, aprendizagem e interação entre jovens e adultos. Pinhais: Editora Melo, 2011.

TAPSCOTT, D. Growing up digital: the rise of the new generation. Nova York: McGraw Hill, 1998. 
VALENTE, C.; MATTAR, J. Second Life e Web 2.0 na educação: o potencial revolucionário das novas tecnologias. São Paulo: Novatec Editora, 2007.

VASINDA, S.; MCLEOD, J.; MORRISON, J. 1+1=3: Combining language experience approach with Web 2.0 tools. LEA SIG (of the International Reading Association) newsletter, 381(1), pp. 6-10. 2007. Disponível em:

< http://juliemcleod.org/portfolio/pdfs/1+1=3.pdf> Acesso em 29 jun. 2014.

VIEIRA, I. L. Leitura na internet: mudanças no perfil do leitor e desafios escolares. In: ARAÚJO, Júlio César (org) Internet e Ensino: novos gêneros, outros desafios.). Rio de Janeiro: Lucerna, 2007. pp. 244-265.

XAVIER, Antonio Carlos. Letramento digital: impactos das tecnologias na aprendizagem da Geração Y. Calidoscópio, Vol. 9, n. 1, pp. 3-14, jan/abr 201. Unisinos Disponível em:< http://revistas.unisinos.br/index.php/calidoscopio/article/view/748/149>

Acesso em 23 jun. 2014. 